\title{
LO SUBLIME POLÍTICO: DEL CIELO ESTRELLADO A LA LEY EN EL CORAZÓN (CON PARADA EN EL PATÍBULO DEL REY)*
}

\author{
JOSÉ M. VÁZQUEZ-ROMERO \\ Universidad Pontificia Comillas, Madrid
}

\begin{abstract}
RESUMEN: Según la estimación kantiana, la ejecución del monarca supone la inversión de la ley y el hundimiento del derecho, hasta el punto de reputarse ese acto como apariencia jurídica. Sin embargo, la aprehensión real o virtual de la escena del ajusticiamiento estremece de tal manera el ánimo del espectador, que tensa su imaginación más allá de sus límites, hasta dar cabida al influjo indeterminado de la razón, único capaz de racionalizar ese espectáculo atroz del caos simbólico. Sólo por medio de ese sentimiento sublime, en el que la imaginación se sale de sus casillas, se consigue transmudar esa escena terrible, haciéndosenos susceptibles al sentimiento moral, por el que resuena la ley moral en la intimidad de nuestra conciencia y que predispone a tomar partido por la revolución como signo del progreso de la humanidad.
\end{abstract}

PALABRAS CLAVE: Kant, derecho, imaginación, sublime, disposición moral, revolución.

\section{The political sublime: from the starry sky to the law in the heart (stopping at the king's scaffold)}

ABSTRACT: According to Kant's conception, the execution of the monarch means the reversal and the collapse of Law to the point of regarding such act as legal appearance. However, the real or virtual apprehension of the execution scene shakes the mind of the viewer in such a way, that it strains his imagination beyond its limits, to accommodate the undetermined influx of reason, which alone can rationalise that atrocious spectacle of symbolic chaos. Only through that sublime feeling, in which imagination flies off the handle, is it possible to transmute that terrible scene, making us susceptible to the moral feeling, for which moral law echoes in the privacy of our consciousness, and which predisposes us to take sides with the revolution as a sign of progress of humankind.

KEY WORDS: Kant, law, imagination, sublime, moral disposition, revolution.

Quizá justamente en las más horrorosas perversiones es preciso admitir la más vasta contribución psíquica a la transmudación de la pulsión sexual. He aqui una obra del trabajo anímico a la que no puede negarse, a pesar de su horrible resultado, el valor de una idealización de la pulsión. Tal vez en ninguna parte la omnipotencia del amor se muestre con mayor fuerza que en estos desvios suyos. En la sexualidad, lo más sublime y lo más nefando aparecen por doquier en intima dependencia ("Desde el cielo, pasando por el mundo, hasta el infierno»).

(Freud, S., Tres ensayos de teoría sexual)

\section{Perversiones del imperativo}

Son de sobra conocidas las reticencias frente a la demarcación kantiana entre doctrina del derecho y doctrina de la virtud. Ciñéndonos a la tradición iusfilosófica española, ya descubrimos que krausistas y filokrausistas fueron

* Este artículo se inscribe en el marco del proyecto de investigación del Plan Nacional I+D+i con referencia FFI2011-23682 
muy sensibles a los presuntos peligros de la separación entre derecho (ley civil) y moralidad (ley moral), censurando que se consideraran la exterioridad y la coerción como los atributos jurídicos por excelencia. Sostuvieron que la pureza vindicada por la doctrina moral kantiana se arruinaría a causa de la indiferencia ante la libre provisión de medios para el cumplimiento de los fines humanos (según ellos, el carácter de la actividad jurídica). De acuerdo con tales presupuestos, advertían, cabría imaginar una sociedad de perversos que mantienen relaciones jurídicas intachables (un orden jurídico sin moral):

Hasta tal punto [los kantianos] llevaron la exageración, que hubo quien dijo, que nada importaba la inmoralidad de los agentes del derecho en un Estado artísticamente constituido; es más, que allí donde el derecho estuviera organizado como una perfecta mecánica, se notaría que coincidía esta ventaja con la inmoralidad de sus individuos; en fin, se llegó a decir que allí está el derecho ejerciendo su verdadero influjo, toda la misión que le está encomendada, donde ningún otro principio existe que sirva de freno á las pasiones ${ }^{1}$.

El dinamismo conflictivo de la historia basado en la insociable sociabilidad (ungesellige Geselligkeit) engranaría la persecución individual de los fines egoístas con una economía restringida del deber —en la que al quantum de delito le corresponde un quantum de castigo proporcional-, resultando, a la postre, suficiente la amenaza exterior del tribunal para hacer composibles los intereses individuales y la convivencia política, pudiendo, en consecuencia, prescindirse de la pureza de la intención moral².

Un paso más, y hasta podríamos revertir los términos y columbrar un estado más pasmoso y obsceno: ese mismo pueblo de demonios actuando moralmente, de acuerdo con la universalidad e incondicionalidad de un imperativo categórico que en nada tuviera que atender al derecho (entendido éste como el conjunto de normas que permiten coexistir a los distintos arbitrios individuales) ${ }^{3}$.

1 ALAs, L., «El derecho y la moralidad»: Revista Europea, t. XII, núm. 240, 29 de septiembre de 1878 , p. 402.

2 Cfr., para una discusión de los pasajes entre derecho y virtud, Vázouez-Romero, J. M., «Aequitas, la divinidad muda. En torno a la referencia equívoca de la virtud en la filosofía práctica kantiana»: Bajo Palabra. Revista de filosofía, época 2, n. ${ }^{\circ} 8$ (2013), pp. 97-111.

3 «Tomemos como máxima universal de nuestra acción el derecho a gozar de cualquier prójimo como instrumento de nuestro placer. [/] Sade demuestra, con mucha coherencia, que esta ley, universalizada, brinda a los libertinos la libre disposición de todas las mujeres indistintamente, consiéntanlo ellas o no, pero que inversamente las libera de todos los deberes que una sociedad civilizada les impone en sus relaciones conyugales, matrimoniales y otras. [.../] Si todos disponen de la misma apertura, se verá que es una sociedad natural. Nuestra repugnancia puede ser legítimamente asimilada a lo que Kant mismo pretende eliminar de los criterios de la ley moral, a saber, un elemento sentimental» (El seminario de Jacques Lacan. Libro 7. La ética del psicoanálisis 1959-1960, Buenos Aires - Barcelona - México, Ediciones Paidós 1988, p. 98; cfr. «Kant con Sade», en Escritos 2, Buenos Aires, siglo veintiuno editores ${ }^{2} 2011$ (2. ${ }^{a}$ reimpr.), pp. 727-751). Esta posibilidad perversa del goce incondicionado se había descartado: «una obligación a gozar es un disparate manifiesto (Eine Verbindlichkeit zum Genießen ist eine offenbare Ungereimheit). Así pues, exactamente lo mismo sucede a propósito de una pretendida obligación de realizar todas las acciones que tienen como fin meramente el goce...» 
Si nos arriesgamos y damos otro paso adelante, hasta podríamos invertir los términos «...tan pronto como imaginamos una escena como la del destino de Carlos I o Luis XVI» ${ }^{4}$. Presentándose como una condena conforme a derecho, la ejecución se representa como una determinación de la voluntad cuya máxima procede de la adopción de una regla universalizable (objetiva); de ahí que, a diferencia del asesinato, «...su máxima no sólo se opone a la ley por defecto (negative), sino incluso dañándola (contrarie) o, como se dice, diametralmente, como contradicción (digamos, de un modo hostil)» ${ }^{5}$. Pero es que todo se juega en el círculo que ese diámetro mide. El sentimiento moral de reprobación procede de esa revolución en la que el ajusticiamiento se representa como una inversión total de los principios jurídicos (del derecho político) por la que el pueblo desplaza y reemplaza al soberano, el padre al que debe su existencia como unidad política.

(Kant, I., Crítica del discernimiento. Edición de Roberto R. Aramayo y Salvador Mas [con estudio preliminar, notas, bibliografía, cronología e índices], Madrid, A. Machado Libros 2003, p. 158; $K U$ B 13*). Sin embargo, se nos advierte, a propósito de esto, que «...el goce mismo no es un estado espontáneo e inmediato, sino que se sostiene por un superyó imperativo: como Lacan subraya una y otra vez, a fin de cuentas el contenido del mandato-superyó es “¡Goza!” (ŽıžEK, S., El acoso de las fantasías, Madrid, Siglo xxi de España Editores 2010, p. 137). Frente a la consideración de que la facultad de desear sólo puede ser determinada patológicamente, «Lacan apunta, por el contrario, a demostrar el estatus trascendental de esta facultad, es decir, a la posibilidad de formular una motivación para nuestro deseo totalmente independiente de la patología (esta causa-objeto no patológica del deseo es el object petit a lacaniano)» (id., p. 227). La insuficiencia kantiana radicaría en que no habría previsto que la acción puesta en obra en conformidad con la inversión de la ley sería tan independiente de la determinación sensible como la que resulta de la máxima que se fundamenta en la ley: «cuando llevo a cabo un acto "sólo porque está prohibido", permanezco dentro del dominio universal-simbólico, sin ninguna referencia a ningún objeto empírico-contundente, es decir, logro lo que es, stricto sensu, un acto no patológico. Entonces, Kant falló así en el cálculo de su apuesta: al limpiar el dominio de la ética de las motivaciones patológicas, quería extirpar la posibilidad misma de hacer el Mal tras la apariencia de hacer el Bien; lo que hizo en realidad fue abrir un nuevo dominio del Mal mucho más extraño que el Mal "patológico"» (id.). Pero, ¿acaso no reconoció que la razón podría, en comandita con la imaginación y en ausencia de la sensibilidad, desmandar fantasiosamente el orden de la necesidad y subrogarlo en una circulación del deseo totalmente enajenada?: «...una propiedad característica de la razón es que puede fingir (erkünsteln kann) deseos con ayuda de la imaginación, no sólo sin contar con un impulso natural encaminado a ello, sino incluso en contra de tal impulso; tales deseos reciben en un principio el nombre de concupiscencia (Lüsternheit), pero en virtud de ellos se fue tramando poco a poco todo un enjambre de inclinaciones superfluas y hasta antinaturales que son conocidas bajo la etiqueta de voluptuosidad (Üppigkeit)»: Kant, I., «Probable inicio de la historia humana», en ¿Qué es la ilustración? Y otros escritos de ética, política y filosofía de la historia. Edición de Roberto R. Aramayo, Madrid, Alianza Editorial 2004, p. 161; Mutmasslicher Anfang der Menschengeschite A 6. (Los textos originales de Kant han sido consultados en: Kant, Werke in zehn Bänden. Herausgegeben von Wilhelm Weischedel). Amén de que puede constatarse que sí conderó la inversión del orden simbólico como resultante de la aplicación de una legislación universalizable en la escena del ajusticiamiento del soberano (cfr. lo que sigue).

4 Kant, I., La Metafísica de las Costumbres. Estudio preliminar de Adela Cortina Orts. Traducción y notas de Adela Cortina Orts y Jesús Conill Sancho, Madrid, Editorial Tecnos ${ }^{4} 2008$ (reimpr.), p. 153.

5 Id. 
La razón de que sea terrible la idea de que un pueblo ejecute formalmente a su monarca es, pues, que el asesinato ha de pensarse solo como una excepción a la regla que el pueblo había erigido para sí mismo en máxima, pero la ejecución ha de pensarse como la total inversión (Umkehrung) de los principios de la relación entre el soberano y el pueblo (éste, que tiene que agradecer su existencia sólo a la legislación del primero, se convierte en soberano de aquél), de suerte que la violencia (Gewaltättigkeit), con la frente bien alta y siguiendo principios, se eleva sobre el derecho más sagrado; lo cual, como un abismo que lo devora todo sin retorno (ohne Wiederkehr), como un suicidio cometido por el Estado, parece ser un delito sin expiación posible ${ }^{6}$.

La inversión del orden: que el hijo (el pueblo) ocupe el lugar del padre (el soberano), provoca un estremecimiento de vértigo por esas alturas desde las que se divisa, abajada, la ley más sagrada, política y genealógica a la vez. La terribilidad del sentimiento de esa violencia elevada (erhoben) - la elevación... ¿hasta el cielo estrellado?, y el abismo... ¿hasta el fondo de los océanos?... entonces, ¿nos atrevemos con lo sublime (Erhaben)? - tendría su razón de ser en lo insaldable de la deuda contraída, que es, precisamente, aquéllo que nos da causa para calificar de apariencia jurídica la formalidad de la ejecución, por cuanto su desmesura viola la proporcionalidad de la acción jurídica, en la que la acción habría de ser conmensurable con la reacción. La contradicción del derecho conlleva que el pensar marre toda referencia y orientación al resultar la imaginación excedida por la demasía del acontecimiento. En consecuencia,

tenemos, pues, razones para admitir que la aprobación de tales ejecuciones no procedía de un principio supuestamente jurídico, sino del miedo del pueblo ante la venganza de un Estado, que podría resurgir (wiederauflebenden) algún día, y que se procedió a aquella formalidad para dar al hecho visos de castigo (Anstrich von Bestrafung), por tanto, visos de procedimiento jurídico (una cosa semejante no sería un asesinato), pero este encubrimiento (Bemäntelung) fracasa porque esta arrogancia del pueblo es peor aún que el asesinato mismo, ya que contiene un principio que haría imposible incluso la regeneración (Wiedererzeugung) de un Estado destruido ${ }^{7}$.

Una inversión de la cual no habría retorno, pues su diámetro sería infinito, su revolución sería sin centro, su principio sería sin génesis, su fundamento sería sin fondo. Sin embargo, ese colapso reflexivo urge a que operen la transmisión y la transferencia (de la ley) —en el límite y sobre el límite- de la contradicción, de la inversión, de la muerte, que, a la postre, habrá que negar y olvidar para racionalizar ${ }^{8}$ Y ello, veremos, por medio de una ficción extrema hasta lo sublime, que no podremos olvidar.

\footnotetext{
6 Id., pp. 153s.; MS Anm. B 210.

7 Met. Cost., cit., p. 154; Anm. B 210.

8 La negación, el olvido se emplazan en-(el)-lugar-del-origen para que advenga la legitimidad republicana: «...es precisamente llegados a este punto cuando podemos hacernos cargo del alcance de la tesis de Kant de que el origen del poder soberano «es inescrutable en sentido práctico». El origen histórico de la composición de un concreto "pueblo soberano» será por lo general una historia de violencia o de una serie de actos de violencia. Pero, pese a
} 


\section{VELADURAS DEL CRIMEN}

Los visos, la pinta, el barniz, la capa (Anstrich) de procedimiento jurídico dados al hecho criminal serían suficientes para no deslegitimar el orden jurídico-político resultante (republicano), por muy ilegítimo que su origen sea: «...si una revolución ha triunfado y se establece una nueva constitución, la ilegitimidad del comienzo y de la realización no puede librar a los súbditos de la obligación de someterse como buenos ciudadanos al nuevo orden de cosas, y no pueden negarse a obedecer lealmente a la autoridad que tiene ahora el poder ${ }^{9}$. ¿Acaso porque el origen legítimo y de la legitimidad estaría ya-y-entonces él mismo sincopado por la ficción que permite unificar el impasse y la representación de la sucesión (tiempo) en el entremedio de la vida y la muerte, en el entredós del vivo y el muerto ${ }^{10}$ ? Esa figuración permitiría tanto contrapo-

ser producto de la violencia, la fuente del derecho, el pueblo soberano (en el estar sometido a las leyes que él mismo se da, y en el dárselas) tiene que ignorar («en sentido práctico», no ciertamente como lección histórica) la violencia de que es producto [...]. [...] si en el origen, el poder soberano no consentía ser excrutado o puesto en cuestión [...], al final el diferenciado soberano republicano quizá siga teniendo aquella misma capacidad de imponerse, pero se ha racionalizado prácticamente hasta el punto de que todo cuestionamiento, para quedar normativamente a la altura del soberano, habrá de efectuarse en términos republicanos, es decir, conforme a los principios de la constitución republicana vigente, esto es, conforme a los mismos principios que constituyen al soberano, de modo que la concreta validez de esos principios es ahora la validez de la facticidad con aquel origen...» (Jiménez Redondo, M., «Introducción», en Habermas, J., Facticidad y validez, Madrid, Editorial Trotta ${ }^{4} 2005$, pp. 33s.). Resta por considerar que quiere decir «no ignorar» como lección histórica (a discutir adecuadamente por el público filosófico) (cfr. infra).

9 Met. Cost., pp. 154s.

10 La ruptura del continuo jurídico habría de reconducirse a la preceptiva continuidad del derecho, como se constata ya en el derecho privado en la figura de la adquisición por contrato. Discutiéndose los actos jurídicos de la posesión inteligible (possessio noumenon), es decir, la posesión hecha abstracción de condiciones empíricas, se asegura que «la transmisión de lo mío mediante contrato se realiza conforme a la ley de la continuidad (Gesetz der Stetigkeit) (lex continui)...» (Met. Cost., p. 94); de no ser así, resultaría asimilada a una adquisición originaria (sin previo poseedor). Pero ello fuerza a dos ficciones. La primera, la representación del acto de transmisión como siendo realizado conforme a una voluntad solidaria de promitente y aceptante y, en definitiva, la idea de una persona moral que responde a la unificación a priori universal de los distintos arbitrios: «...esta continuidad lleva consigo que no sea uno de ambos (promittentis et acceptantis) en particular, sino su voluntad unificada la que transmite lo mío a otro...» (id.). La segunda, la representación de la posesión del objeto como perteneciente, por un instante, a ambas partes a la vez: «...por tanto, ambos actos -el de la promesa y el de la aceptación- se representan, no como mutuamente sucesivos, sino (cual pactum re initium) como surgiendo de una única voluntad común (lo cual se expresa mediante la palabra "simultáneamente")...» (p. 92). El empleo de la ficción jurídica en el derecho de sucesiones romano como sutura para las soluciones de continuidad jurídicas es paradigmático, revelándose como «muerte», «legado» y «subjetividad» resultan inextricables en el trance, el lance y el desenlace ficcionales: «après la mort, cependant, l'heritier désigné par le testament devait accepter la succesion et entrer en possesion de son nouveau bien. Mais comment faire entre-temps? Plusieurs expédients furent essayés, dont celui qui laissait 
ner vis-à-vis a soberano y súbdito, «...porque desde un punto de vista jurídico, [pueblo y soberano] son siempre dos personas morales diferentes.... ${ }^{11}$, como permutar a uno por el otro.

Sea como sea, la metafísica de las costumbres no puede pasar por alto esa idea que resulta inasequible para nuestro entendimiento - de lo extremadamente malo (bloße Idee des Äußerst-bösen), el crimen de maldad formal (ein Verbrechen einer förmlichen Bosheit): «hasta donde alcanza nuestra capacidad de comprensión (so viel wir ensehen), es imposible que los hombres cometan semejante crimen de maldad formal (completamente inútil) y, sin embargo, no se le puede omitir (nicht zu übergehen) en un sistema de la moral (aunque se trate de la mera idea de lo extremadamente malo)» ${ }^{12}$. No se puede pasar por alto y cambiar de tema, porque nos jugamos la seriedad que pudiera concederse a la imaginación al entregarla a una finalidad más elevada que la de achicar nuestro ánimo, por pereza o cobardía, y limitarla a la exhibición sensible del miedo. Habremos de atrevernos a recibir una finalidad suprasensible, sobre todo allí donde el caos práctico más exige una disposición moral para la determinación racional de nuestra voluntad.

El expediente por el que se desencubre la ejecución del soberano como causada por el miedo, y se resuelve considerar el procedimiento jurídico como cobertura (Anstrich), estribaría en la proyección pragmática de nuestra limitación cognoscitiva (hasta donde alcanzamos a ver...), pero resulta tanto

provisoirement et fictivement le défunt en place de maître-un maître dont la mort était en quelque sorte remise à plus tard. Puis on se mit d'accord, dans le courant du $\mathrm{II}^{\mathrm{e}}$ siècle de notre ère, pour considérer que le maître n'était autre que la succession elle-même [.../] La succession légale intestat soulevait d'autres types de difficultés [...]. La Loi des Douze Tables (450 avant J.-C.) laissait les biens aux descendants sous puissance: de tels héritiers étaient saisis comme "héritiers siens" du mort, comme ses sui heredes. Les premiers exégétes se servirent de ce verset pour s'assurer de l'instantanéité de la succession, pour faire qu'elle se produisît à l'instant même, sous la puissance juridique du mourant, in potestate morientis. Le transfert n'opérait ainsi qu'à l'ultime moment: la puissance de transmettre habitait un père en même temps en vie et en mort. En ce contexte singulier, l'équivalence est frappante, dans les textes juridiques latins, entre les expressions "il meurt" (i.e. dejà) et "il vit" (i.e. encore): moriente eo et vivo eo. La frontière se considère sous les deux versants du mourir et du vivre, elle se saisit sous les deux côtes d'un même instant. L'héritier sien advenait du plein droit au seul momento de la mort du père, sans aucune prise de possesion. La mort n'ouvrait dans le temps aucune vacance. Rien ne semblait interrompu par elle.[/] Pour consolider cet effet d'imméditeté, les juristes de l'époque classique tentèrent d'en rationaliser encore davantage le principe. Ils postulèrent que tout se passait comme si l'héritier continuait d'être, après la mort du père, ce qu'il avait été dejà avant elle: le maître des biens [.../] À l'illusion qu'au moment de la mort la personne de l'héritier libre et maître de son bien paraissait avoir été celle déjà du fils sous puissance, s'ajoute une seconde illusion, qui vient compléter et prolongar la première. Il semblait aussi que l'on passât continûment de la personne du mort à la personne du vivant, de la personne du père à la personne du fils, comme si une seule et même personne, pour ainsi dire, se fût prolongée à travers les biens» (Thомаs, Y., Les opérations du droit, Seuil/Gallimard, novembre 2011, pp. 195-197).

11 Met. Cost., p. 152.

12 Id., p. 153; Anm. B 209. 
más cuestionable cuanto que ya el asesinato del monarca, desnudo de visos o veladuras jurídicas, aparece ya reenviado al miedo, aus Furcht, a ese mismo miedo a la reacción al que se reduce también la ejecución formal: «entre todas las atrocidades que conlleva un golpe de Estado por insurrección, el asesinato mismo del monarca no es todavía lo más grave, porque cabe pensar que el pueblo lo hace por miedo de que, si sobrevive el monarca, pueda recuperarse de nuevo y hacer sentir al pueblo el castigo merecido...»"13. Siendo así, ¿por qué aclarar, entonces, que no se trata de una condena formal («...no se trataría de una disposición de la justicia penal, sino únicamente de una disposición de la autoconservación ${ }^{14}$ ), si no es para equiparar el asesinato a la ejecución, pues ambos proceden de idéntica causa (el miedo)? Sin embargo, ¿cómo concebir, entonces, la terrible formalidad suplementaria del ajusticiamiento -que no sólo se opone a la ley por defecto (abbruchsweise) (negative), como el asesinato, sino que la invierte diametralmente, como contradicción? Si concluimos que los revolucionarios barnizan su crimen recurriendo a esa formalidad, ¿no resulta extravagante disimular subrepticiamente el miedo con el pánico, lo malo con lo monstruoso, la excepción con la inversión, y más cuando la angustia nos invade tan pronto recordamos la escena, «que conmueve el alma imbuida de la idea del derecho humano con un estremecimiento que se renueva tan pronto como imaginamos una escena...» ${ }^{15}$ ? ¿Sería el derecho, entonces, un velo de la dominación que disimularía su máquina y se velaría a sí mismo (al propio orden constitucional)? Pero, entonces, podríamos, de un salto, levantarlo y desnudar el origen violento y la violencia originaria. ¿No sería como asomarse al borde del abismo y arriesgarse, en lo sucesivo, a exponer la ley como mero revestimiento de la opresión y la violencia y, en consecuencia, arruinar definitivamente la legitimidad del orden político, violando el precepto que proscribe la investigación del origen del poder: «...el súbdito no debe sutilizar activamente (...soll nicht $[. .$.$] werktätig vernünfteln) sobre este origen.... { }^{16}$ ? La racionalización (vernünfteln) de la insumisión frente al orden político, incluso frente al nuevo régimen (republicano), encontraría apoyo en tal desencubrimiento del derecho como viso del crimen. ¿No se expone esa inversión, que deja desnudo aquéllo (el derecho) que pretende investir con ese ajusticiamiento, a que cualquier niño grite: «¡Pero si no lleva nada!»? Pero es que el poder se desfonda del todo si con una exhibición como el ajusticiamiento, en el que la ley es dada la vuelta y convertida en traje a la medida del miedo, esas telas ya no son vistas por quienes ignoran su filiación y quebrantan la genealogía ${ }^{17}$. La ficción no

\footnotetext{
13 Met. Cost., p. 152.

$14 \quad I d .$, p. 153.

15 Id.

16 Met. Cost., pp. 149s.; B 203. Cfr. nota 8.

17 «-Señor conde - dixo Patronio-, tres omnes burladores vinieron a un rey et dixiéronle que eran muy buenos maestros de facer paños, et señaladamente que fazían un paño que todo omne que fuesse [fijo] daquel padre que todos dizían, que vería el paño; mas el que non fuesse fijo daquel padre que él tenía a que las gentes dizían, que non podría ver el paño»
} 
habrá de envolver el miedo por las consecuencia del nudo crimen en el sudario de la ley, porque el precio de tal viático es impagable, sino que habrá de resolverse a aprehender el asesinato bajo el aspecto (Anstrich) de la ejecución, como-si fuera una ejecución: en la exhibición ante la cual la imaginación resulta impotente.

\section{Sublimidades del VÉRTigo}

Pero, ¿cómo se va a saltar el abismo (la inversión del derecho) que abre la ficcionalidad de la formalidad jurídica, si no alcanzamos a ver, si no se puede pasar por alto (nicht zu übergehen), más aún cuando los hombres se han acostumbrado por pereza y cobardía a caminar con andaderas (Gängewalgen), y aun «quien lograra quitárselos (los "grilletes", Fußschellen) acabaría dando un salto inseguro para salvar la más pequeña zanja (über den schmalesten Graben einen nur unsicheren Sprung tun) al no estar habituado a semejante libertad de movimiento» ${ }^{18}$. Sin embargo, se exige atreverse a sincopar ese abismo del que

(Don Juan Manuel, El Conde Lucanor o Libro de los Enxiemplos del Conde Lucanor et de Patronio, Madrid, Editorial Castalia 1969, p. 179).

18 «Contestación a la pregunta: ¿Qué es la Ilustración?», en ¿Qué es ilustración? Y otros escritos..., cit., p. 84; A 483. El abandono del estado de naturaleza y el comienzo de la historia de la humanidad arranca con una desplazamiento organoléptico en el que se prefigura y preludia el sentimiento de lo sublime. Es cuando el hombre se atreve a catar aquéllo que los sentidos emparentados del olfato y el gusto no acreditan como fruto seguro, arriesgándose, en seguida la razón comenzó a despertarse dentro de él, a acreditar el bocado como similar a los acostumbrados con las noticias de otro sentido menos ligado al instinto, como la vista, con lo que la imaginación y la razón se eximen del impulso natural (Naturtrieb) y conducen al conocimiento y al goce que nos distinguen de los animales y que presuponen el uso de la libertad: «éste [el hombre] descubrió dentro de sí una capacidad para escoger por sí mismo su propia manera de vivir y no estar sujeto a una sola forma de vida como el resto de los animales. A la satisfacción momentánea que pudo provocarle el advertir ese privilegio, debieron seguir de inmediato el miedo y la angustia (Angst und Banigkeit): cómo debía proceder con su recién descubierta capacidad quien todavía no conocía nada respecto a sus cualidades ocultas y efectos remotos» ("Probable inicio de la historia humana», en ¿Qué es la Ilustración? Y otros escritos..., cit., p. 162; "Mutmaßlicher Anfang der Menschengeschichte», A 7). Esa angustia que no se reduce a la aprehensión ante algo que aceche, el miedo concreto al fruto malsano, sino que consiste en un sentimiento radical de inseguridad, que no procede de la representación del objeto, sino del desbordamiento de los límites de la imaginación: «se encontró, por decirlo así, como al borde de un abismo, pues entre los objetos particulares de sus deseos - que hasta entonces le había consignado el instinto- se abría ante él una nueva infinitud de los deseos cuya elección le sumía en la más absoluta perplejidad; sin embargo, una vez que había saboreado el estado de la libertad, ya le fue imposible regresar al de servidumbre (bajo el dominio del instinto)» (p. 162, A 7). Ese imposible retorno al estado de naturaleza marca el comienzo de la historia humana. El progreso de la intuición más allá del instinto conmociona a la imaginación, que padece de vértigo ante la ilimitación del deseo, urgiendo a un cambio de régimen, en el que la razón releve al instinto y domine esa serie infinita que nos abisma. Algunos eslabones de la argumentación son rousseaunianos, como la 
pudiera no haber vuelta (ohne Wiederkehr), y, si no saltar el abismo insondable, sí vadear su diámetro infinito, como condición para pensar y dominar la violencia excesiva, lo excesivo de la violencia. Así como «...aunque sólo sea para poder pensar sin contradicción el infinito se exige en el ánimo humano una capacidad que es ella misma suprasensible» ${ }^{19}$, así, para poder revertir la gravitación de ese abismo que todo lo devora, se exigirá un impulso absolutamente poderoso de despegue.

Ello provocará en la imaginación una tremenda tensión que resquebraja su función de mediación entre el pensar y la intuición. La aprehensión de la ejecución del monarca resultaba contradictoria para nuestro entendimiento, por lo que sólo cabía juzgarla de mascarada jurídica del crimen; sin embargo, la razón exigía ir más allá de esos límites del representar y arrostrar la (im-)posibilidad del mal extremo, si es que la unificación del poder y del deber habría de fundamentarse en un sistema de la moralidad. Sólo exponiendo la imaginación a la (im-)posibilidad del desacuerdo entre la sensibilidad y el entendimiento, es decir, sólo suspendiendo la propia síntesis trascendental de la imaginación sería posible tomarle la medida al diámetro infinito del abismo:

Lo excesivo para la imaginación (hasta donde es impelida [getrieben wird] en la aprehensión de la intuición) es, por así decirlo, un abismo donde ella misma teme perderse (ist gleichsam ein Abgrund, worin sie sich selbst zu

discriminación de los sentidos o esa valoración de la imaginación, pero la cadena es grande, como lo muestra la relación derridiana, que engancha el comentario de que «Freud se mete en consideraciones sobre el concepto de represión, sobre la hipótesis de su origen orgánico ligado a la postura erguida, dicho de otro modo, a cierta elevación», con la siguiente nota: «habría que encadenar este argumento con el que dirá [Freud] más tarde sobre Kant, sobre el imperativo categórico, sobre la ley moral en nuestro corazón y el cielo estrellado por encima de nuestras cabezas» (Derrida, J., Prejuzgados. Ante la ley, Avarigani editores, 2011, p. 38), apuntándosenos, a continuación, lo que esa elevación eleva: «el paso a la situación erguida endereza o eleva al hombre que aleja así la nariz de las zonas sexuales o genitales» (pp. 38s.). Se trataría de una erección similar a la del sentimiento de lo sublime que analizamos; se parte, en un caso, de la escena ominosa de la ejecución, en el otro, del olfateo nauseabundo de los genitales, pero, en ambos, se llega hasta la ley moral. La ascensión, en todo caso, no está exenta del consabido vértigo que produce la posibilidad de que la ley se ausente de sí: «...si el sujeto experimenta algo que se parece a un curioso vértigo es porque el Otro como objeto del deseo es percibido como falo y, en cuanto tal, es percibido como falta en el lugar de su propio falo. Alguien me lo ha llegado a comparar con una especie de vértigo metafísico, experimentado en otras circunstancias, de lo más infrecuentes, a propósito del propio ser, como subyacente a todo lo que es» (El seminario de Jacques Lacan. Libro 5. Las formaciones del inconsciente 1957-1958, ed. cit., 2009, $8^{\text {a }}$ reimpr., p. 393). ¿Alguien?: «El ente es conocido - ¿pero conocemos el ser? ¿No nos sobrecoge un vértigo (Befällt uns nicht der Schwindel...?) cuando tratamos de determinarlo o siquiera de aprehenderlo en sí mismo? ¿No es el ser semejante a la nada?» (Heidegger, M., Kant y el problema de la metafísica, § 41, México D. F., Fondo de Cultura Económica ${ }^{2} 1986$ [1. ${ }^{\mathrm{a}}$ reimpr.], p. 190; más adelante, § 43: «la angustia es el encontrarse-fundamental que nos coloca frente a la nada. Pero el ser del ente sólo es inteligible - y en ello se encuentra la más profunda finitud de la trascendencia- si el ser-ahí, en el fondo de su esencia, se asoma a la nada [in das Nichts hineinhält]», p. 199).

19 Crít. disc., p. 212; B 92. 
verlieren fürchtet). Sin embargo, producir un esfuerzo tal de la imaginación no es excesivo para la idea de la razón suprasensible, sino que es conforme a su ley: por tanto, es de nuevo (wiederum) atractivo exactamente la misma medida en la que era repulsivo para la mera sensibilidad (mithin in eben dem Maße wiederum anziehend, als es für die bloße Sinnlichkeit abstoßend war $)^{20}$.

20 Crít. disc., p. 216; B 98-99. «El “complacerse-en” de lo sublime es pura o simplemente negativo (nur negativ) en la medida en que suspende el juego y eleva a lo serio. En este aspecto, constituye una ocupación relacionada con la ley moral. Tiene una relación esencial con la moralidad (Sittlichkeit) que supone también una violencia contra los sentidos. Pero la violencia es aquí un hecho de la imaginación, no de la razón. La imaginación vuelve esta violencia contra ella misma, se mutila, se maniata, se venda a sí misma. Es en este lugar que el valor de sacrificio obra temáticamente en el interior de la tercera Crítica, mientras que la acosamos ahí constantemente. Pero esta violencia mutilante y sacrificial organiza la expropiación en el interior de un cálculo; y el posterior intercambio es justamente la ley de lo sublime tanto como lo sublime de la ley. La imaginación gana en lo que pierde. Gana perdiendo. La imaginación organiza el rapto (Beraubung) de su propia libertad, se deja mandar por otra ley distinta del uso empírico que la determina con vistas a un fin. Pero mediante esta renuncia violenta gana en extensión (Erweiterung) y en potencia (Macht). Esta potencia es más grande que el sacrificio, y si el fundamento se le oculta, la imaginación tiene la impresión del sacrificio y del rapto al mismo tiempo que de la causa (Ursache) a la cual se somete» (Derrida, J., La verdad en pintura, Buenos Aires - Barcelona - México DF, Paidós 2001, p. 139). Habría que insistir en que esa ganancia de la imaginación, que amplía su poder, conlleva ciertas cargas, sobre todo por cuanto se reembolsa con un pagaré emitido desde un fundamento oculto del cual se convierte en apoderada. El sacrificio de la imaginación — de su libertad- lo es en aras, en el ara, de lo suprasensible. Entonces, ¿se limita la razón a ilimitar?: «...una razón que se limita a ampliar a esa imaginación con la cual está conectada... (...der Einbildungskraft, und einer, obschon ganz ohne bestimmten Zweck damit in Verbindung gesetzen, jene bloß erweiternden Vernunft...)» (id., p. 214; B 95). La imaginación es llevada más allá de sí en la experiencia de lo sublime: empujada por la intuición, sin que el temor sirva de freno, y, a la vez, tensada por la razón, que estropeará su juego: «en esta medida, en tanto que emoción, [lo sublime] no parece ser juego alguno, sino que otorga seriedad a la ocupación (Beschäftigung) de la imaginación» (p. 200, B 75). Que ejerza la violencia sobre sí supone que, a través de ella (durch die Einbildungskraft selbst), la libertad, que juega en el sentimiento de lo bello, se emplea en el sentimiento de lo sublime como instrumento de la razón: "...la libertad se representa tanto más en el juego que en cualquier asunto legal, que es la auténtica índole de la moralidad de los seres humanos, donde la razón tiene que violentar a la sensibilidad (...die Freiheit im Spiele, als unter einem gesetzlichen Geschäfte vorgestellt: welches die echte Beschaffenheit der Sittlichkeit des Menschen ist, wo die Vernunft der Sinnlichkeit Gewalt antun muß). Sólo que en el juicio estético sobre lo sublime esta violencia se representa como ejercida por la misma imaginación en tanto que herramienta de la razón (als einem Werkzeuge)» (Crít. disc., p. 229; B 116-117; otra traducción de parte del pasaje: «...mediante él [el placer inmediato en lo bello de la naturaleza] la libertad es representada en el juego, más bien que en una ocupación, conforme a la ley, que es la verdadera propiedad de la moralidad del hombre, en donde la razón debe hacer violencia a la sensibilidad...» [Crítica del Juicio. Traducción del alemán por Manuel García Morente, Madrid, Espasa-Calpe 1977, p. 172]). Todo lo cual acuerda con la condición medianera de la imaginación: un toma y daca en el que lo excesivo de la aprehensión la paraliza como capacidad representativa, pero, en virtud de esa impotencia, la ofrenda para la recepción de esa nueva ley imponente. Sin duda, su estatuto no es el de fundamento de esa ley, que no se presenta y para el que resta inadecuada, sino 
De nuevo, o de vuelta (wiederum), de vuelta de ese pozo de gravedad sin retorno (ohne Wiederkehr), en el que cae la imaginación presa del miedo cuando evoca el patíbulo del monarca, y adonde la razón ha de descender para hacer valer su ley, forzando a elevarse al abismo hasta retornar a la unidad, completando así la revolución. Por todo ello, sería obligado atreverse interiormente con el estremecimiento que provoca la inversión de la ley como consecuencia de esa forma de exhibición desviada que es la ejecución del monarca.

No hay que preocuparse porque el sentimiento de lo sublime se pierda por una forma desviada de exhibición (abgezogene Darstellungsart) tal que con respecto a lo sensible se torna totalmente negativa, pues la imaginación, si bien, ciertamente, nada encuentra por encima de lo sensible donde pueda detenerse, también se siente, sin embargo, ilimitada por esta destrucción de sus límites. Así pues, aquella desviación (Absonderung) es una exhibición de lo infinito, lo cual ciertamente, justo por ello, sólo puede ser una exhibición meramente negativa, pero que sin embargo amplía el alma ${ }^{21}$.

La interpretación de la ejecución formal del soberano como apariencia jurídica no espanta del ánimo el espanto que sentimos, en el ínterin,

el de franquía del mandato que recibimos de esa ley: el sentimiento moral, el respeto (Achtung), que se abre hasta el desquiciamiento de la representación cuando se lleva hasta el límite la tensión (Anspannung) que soporta la imaginación. Estamos repitiendo aquí, para desplazarla, la encrucijada de la interpretación heideggeriana de la fundamentación de la metafísica, que entiende a la imaginación trascendental como la raíz de la que son ramas la intuición y el pensar puro, donde se incluye, claro está, la razón práctica: «la entrega inmediata a... que se somete, es la receptividad pura; la libre imposición de la ley es la espontaneidad pura; pues ambas están en sí unidas originariamente. Y, a su vez, sólo el origen de la razón práctica en la imaginación trascendental permite comprender por qué, en el respeto, no se aprehende objetivamente ni la ley ni el sí-mismo que actúa, sino que se patentizan ambos de una manera más originaria, no objetiva y no temática, como un deber y un actuar que forman el ser-mismo no reflexionado y actuante» (HeIDEGGER, M., Kant y el problema de la metafísica, cit., pp. 138s.). Si bien es cierto que se reconoce que ahí no se aborda la reaparición de la imaginación pura en la tercera crítica (cfr. pp. 139s.), sí se concluye que en la segunda edición de la primera crítica el estatuto originario y central de ésta se suprime y subroga. "¿Acaso la Crítica de la razón pura no se priva a sí misma de su tema, si la razón pura se convierte en imaginación trascendental? ¿No nos conduce esta fundamentación a un abismo?» (id., p. 144). Y, como ocurre ante ese abismo, que todo lo devora, uno se asusta y retrocede ante lo pavoroso (schreckte, no fürchtet), pero, a la vez, se expone para ser abducido por una fuerza mayor: «Kant, por el radicalismo de sus preguntas, llevó la "posibilidad" de la metafísica al borde de este abismo (vor diesen Abgrund). Vió lo desconocido y tuvo que retroceder. No fué únicamente la imaginación trascendental la que le produjo temor, sino que, mientras tanto, la razón pura como tal lo había atraído con mayor fuerza (Denn das allein war es nicht, daß ihn die transzendentale Einbildungskraft schreckte sondern daß inzwischen die reine Vernunft als Vernunft ihn noch stärker in ihren Bann gezogen hatte)» (id.; Kant..., Frankfurt am Main, Vittorio Klostermann 1991, p. 168). ¿No es ese el paso, el salto del sentimiento de lo sublime: la imaginación aterrada, y justoa-continuación, la razón que abduce?

${ }_{21}$ Crít. disc., p. 236; B 124. 
momentáneamente (Augenblick), ante ese hecho monstruoso ${ }^{22}$. Ese desplazamiento de (i) la inclinación sensible a la supervivencia (miedo) a (ii) su presentación negativa como ficción jurídica del procedimiento penal, aun a sabiendas de ser contrafáctico ${ }^{23}$, deja en suspenso el derecho, no ya como estado de excepción, sino como inversión del estado. Pero para forzar simultáneamente, en su formalidad informe, a discernir subjetivamente ese estremecimiento que la exhibición monstruosa de la ejecución del soberano provoca, para poder probar que, más allá de su monstruosidad, la razón domina el sentimiento que desborda la imaginación: que lo máximamente grande de la naturaleza se eleve hasta adecuarse con la razón, que el abismo de la violencia se empine hasta la razón. Sólo si juzgamos estéticamente como sublime ese terrible sentimiento moral que provoca la ejecución del soberano en la revolución, y probamos así la superioridad de lo suprasensible de las ideas de nuestra razón, a lo que nos aboca ineluctablemente el atentado consistente en violentar el mismo fin que constituye el concepto de la ejecución (la ley moral que funda el derecho), podremos cancelar lo monstruoso.

Esta reflexión del discernimiento estético para alzarse (zu erheben) hasta conseguir adecuarse con la razón (zur Angemessenheit mit der Vernunft) (mas sin un concepto determinado de ella) representa al objeto -incluso mediante la inadecuabilidad objetiva de la imaginación (selbst durch die objektive Unangemessenheit der Einbildungskraft) — en su máxima amplitud (Erweiterung) para la razón (en tanto que capacidad de ideas), mas como ampliación subjetivamente teleológica (durch als subjektiv-zweckmäßig vor) ${ }^{24}$.

22 «Un objeto es monstruoso (Ungeheuer) cuando mediante su magnitud aniquila el fin que constituye su concepto» (Crít. disc., p. 210; B 89). La reunión de la libertad y de la coacción por el deber, que no por el miedo, exigirá no sólo la simbolización de las ideas morales que depara la concordancia del gusto por lo bello con lo bueno, sino la superación de la discordancia entre la imaginación y el entendimiento —el desfondamiento de la imaginación por lo sublime- que se expone en el espectáculo monstruoso y, por ende, contradictorio, de la ejecución real, el cual desborda cualquier analogía entre intuición y concepto (cfr. infra).

23 «La fiction es un procédé qui, on l'a assez souvent signalé, appartient à la pragmatique du droit. Elle consiste à d'abord travestir les faits, à les déclarer autres qu'ils ne son vraiment, et à tirer de cette adultération même et de cette fausse supposition les conséquences de droit qui s'attacheraient à la vérité que l'on feint, si celle-ci existait sous les dehors qu'on lui prête. [/] [...] la fiction requiert avant tout la certitude du faux. [...]. La présomption intègre l'imperfection de la connaisance humaine, le droit revêtant alors d'une apparence de certitude un probable qui ne peut être et éternellement débattu. La fiction procede d'une démarche résolument contraire, même si les résultats auxquels elle conduit sont parfois empiriquement comparables. Elle ne se contente pas de mettre un terme à la recherche du vrai: c'est cette recherche même que, d'emblée, elle répudie. La fiction est une négation du vrai manifeste; elle transgresse, pour le fonder autrement, l'ordre même de la nature des choses "en tirant un droit certain d'un fait sur lequel elle statue en sens contraire" (ius certum de aliquo facto fingit statuando in oppositum, Panormitain sur c. 30, X 4, n. 6)». (Thomas, Y., Les opérations du droit, cit., pp. 133-135).

${ }_{24}$ Crít. disc., p. 230; B 118. 


\section{SUBREPCIONES DEL SENTIMIENTO}

Es cierto que el sentimiento experimentado no se juzga estético, ya que no consiste en el disgusto provocado porque la exhibición de la desdicha del ajusticiado repugne patológicamente a nuestra idea del bien moral ${ }^{25}$, sino que se califica de sentimiento moral (moralische Gefühl): «¿cómo explicar [...] este sentimiento, que no es aquí estético (una compasión, efecto de la imaginación, que se pone en el lugar del que sufre), sino moral...? ${ }^{26}$. En cuanto tal, habría de provenir de la previa representación de la ley moral. Sin embargo, esa cualificación que previene de reducir la calidad del sentimiento a la intuición del objeto resulta insuficiente para su explicación, que se sigue demandando: ¿cómo explicar, sin embargo, este sentimiento...? Y ello, porque la escena aprehendida contradiría la validez formal de la ley fundamental y del fundamento legal, escenificando el círculo de su autocontradictoriedad (performativa) al establecerla como regla para una máxima que la niega: «...rechaza la autoridad de la ley misma, de cuya validez no puede abjurar, sin embargo, ante su razón, y convierte en regla de su acción obrar contra la ley, sin negarle formalmente evidencia... (...verwirft er die Autorität des Gesetzes selbst, dessen Gültigkeit er sich doch vor seiner Vernunft nicht ableugnen kann, und mach er sich zur Regel, wieder dasselbe zu handeln...) ) ${ }^{27}$. Se le hace imposible a la imaginación representarse tal intuición teleológicamente, pues se trata de una representación que desfonda cualquier finalidad, pareciendo así hasta desfondarse la precedencia trascendental de la ley. Por ello, aunque resulte desproporcionada para nuestra imaginación la posibilidad de un hecho tal, y ello dé razones para concebir que su apariencia jurídica es causada por el miedo, sin embargo, esa exhibición de violencia elevada hasta hollar las alturas de la ley, esa representación de ese crimen incomparable para el que no hay expiación posible, provoca un conflicto en la imaginación como capacidad de dar imagen, que fuerza a que seamos capaces de transfigurar tal intuición según la legalidad que ha de prevalecer, la de nuestra razón (práctica). Será conforme a los principios de la razón la exigencia de cohonestar esa conmoción del ánimo con la finalidad suprasensible de nuestras ideas (prácticas), pues «...la misma violencia (Gewalt) que padece el sujeto por medio de la imagina-

25 «Alegrarse con otros y sufrir con ellos (sympathia moralis) son sin duda sentimientos sensibles de placer o desagrado (que, por tanto, han de llamarse estéticos) (darum ästhetisch zu nennenden) por el estado de satisfacción o de dolor ajenos (simpatía, sentimiento de compartir) (Mitgefühl, teilnehmende Empfindung), para los cuales ya la naturaleza ha hecho receptivos a los hombres» (Met. Cost., p. 327; A 129-130).

26 Met. Cost., p. 153; Anm. B 208. ¿De dónde proviene esa disposición del ánimo para experimentar ese sentimiento ante una conmoción de los fundamentos jurídicos tal que los invierte? De entrada, ésta parece rebasar el marco de la catarsis aristotélica, en la que la purgación de las afecciones se realiza por medio de la compasión y del miedo ( $\delta$ ’ ع $\lambda$ ćou kaì $\varphi$ ó cfr. Poét. 49b27), compasión (o simpatía) y miedo que son recusados como ingredientes de la emoción que provocaría el espectáculo del ajusticiamiento monárquico.

27 Met. Cost., p. 153; Anm. B 209. 
ción, se enjuicia como teleológica para la determinación total del ánimo» ${ }^{28}$. La teleología de esa violencia releva, entonces, lo monstruoso por lo sublime, al convocar a nuestra disposición moral.

La condición para ese juicio es que no seamos víctimas nosotros también de ese temor que confunde a los actores de la revolución, porque entonces seríamos arrebatados por un encubrimiento análogo al que ellos padecen al velar el asesinato con vestiduras procesales. Consiste éste en la subrepción (Subreption) que confunde al enjuiciamiento estético de lo sublime cuando se pretende fundamentarlo objetivamente. Si así fuera, el derecho se precipitaría en la monstruosidad del hecho (la ejecución del monarca), que contradice el fin de la humanidad. En vez de ello, por el contrario, se debe revalidar subjetivamente la confianza en el poder de someter teleológicamente tal aprehensión: «...aquello que, sin sutilezas, meramente en la aprehensión provoca en nosotros el sentimiento de lo sublime (según la forma ciertamente de manera contraria al fin e impropia para nuestro entendimiento) puede parecer inadecuado para nuestra capacidad de exhibición y, por así decirlo, hacer violencia a la imaginación (...un gleichsam gewalttätig für die Einbildungskraft ersecheinen mag...), pero, justo por ello, se juzgará como tanto más sublime» ${ }^{29}$.

Ahora bien, el sentimiento de lo sublime requiere de la seguridad que depara la distancia adecuada a la inadecuación de lo sublime, condición para la unificación de lo grande o poderoso sin parangón ${ }^{30}$. Sin ese alejamiento no hay respeto, sino que sólo tendríamos miedo. Sólo así, por el sentimiento de lo sublime, que no por las afecciones provocadas por la simpatía y/o el miedo, resulta purificado el espectáculo monstruoso de la ejecución y puede participarse e impartirse el discurso ilustrado sobre la revolución. La revolución, si bien siempre injusta (ungerecht) ${ }^{31}$, no debe ser juzgada interesadamente, como activistas, sino desinteresadamente, como espectadores; sólo así puédese apreciar su magnitud incomparable, pues «este acontecimiento no consiste en las relevantes acciones o en los alevosos crímenes ejecutados por los hombres, merced a lo cual se empequeñece lo que era grande entre los hombres o se engrandece lo que era pequeño... (...wodurch, was gro $\beta$ war, unter Menschen klein, oder was klein was, groß gemach wird...)»32. Grandioso como sublime:

28 Crít. disc., p. 217; B 100.

29 Crít. disc., pp. 200s.; B 76.

30 «Cabe así explicarse lo que Savary señala en sus noticias sobre Egipto: que para recibir la emoción de la magnitud de las pirámides uno no puede ni acercarse mucho a ellas, ni tampoco debe alejarse mucho» (Crít. disc., p. 208; B 88).

31 «La revolución de un pueblo pletórico, que estamos presenciado en nuestros días, puede triunfar o fracasar, puede acumular miseria y atrocidades en tal medida que cualquier hombre sensato (wohldenkender Mensch) nunca se decidiese a repetir un experimento tal costoso, aunque pudiera esperar llevarlo a cabo venturosamente al emprenderlo por segunda vez...» (El conflicto de las Facultades en tres partes, cit., p. 160; A 144-145).

32 Id., p. 159; A 142-143. 
Llamamos sublime a aquello que es grande sin más (Erhabene nennen wir das, was schlechthin gro $\beta$ ist). [...]

$[\ldots]$

Pero si llamamos a algo no sólo grande, sino grande sin más, absolutamente grande, grande desde todo punto de vista (por encima de toda comparación), esto es, si lo llamamos sublime (Wenn wir aber etwas nicht allein gro $\beta$, sondern schlechthin-, absolut-, in aller Absicht- [über alle Vergleichung] gro $\beta, d . i$. erhaben), se ve entonces pronto que no consentimos buscar para este algo un patrón de medida adecuado a él fuera de él, sino sólo en él. Es una magnitud idéntica tan sólo consigo misma. De ello se sigue que no hay que buscar lo sublime en las cosas de la naturaleza, sino sólo en nuestras ideas....33.

Ni espigando entre las hazañas heroicas, ni entre los crímenes ominosos, hallaremos el acontecimiento que da ocasión para poder pensar el progreso de la humanidad; bien entendido que la virtualidad filosófica de ese hecho no es positiva (objetiva), sino negativa (subjetiva). «No, nada de eso. Se trata simplemente del modo de pensar de los espectadores que se delata públicamente ante esta representación de grandes revoluciones...» ${ }^{34}$.

\section{Simbolizaciones del PENSAR}

El sentimiento que arrebata el ánimo con ocasión de un hecho de grandeza incomparable, die Revolution, hay que remitirlo a la subjetividad de la representación, que no a la objetividad de la afección; pero no se trata de la exaltación de los revolucionarios, arrastrados por el estrépito de la revolución y por el miedo a la reacción, sino de la expectación exaltada, si bien desinteresada, del ilustrado. Se trataba de ese deseo que el público espectador declara públicamente - su toma de partido, la participación de su deseo (eine Teilnehmung dem Wunsch)_, simpatizando con exaltación: «...una exaltación con la que simpatizó el público que contemplaba todo ello desde fuera... (...mit welcher Exaltation das äußere zuschauende Publikum dann, sympathisierte)!»35. Una exaltación, no obstante, como la que corresponde al sentimiento sublime, que se eleva hasta lo alto, pero desde fuera (das außere), sin la menor intención de tomar parte, de corresponder (ohne die mindeste Absicht der Mitwirkung), desinteresadamente, en virtud de su desinterés (der Uneigennützigkeit wegen) ${ }^{36}$. Por ello, la exaltación

33 Crít. disc., p. 203, p. 206; B 80, 84.

34 El conflicto de las Facultades, p. 159. "Pues ese acontecimiento es demasiado grandioso (zu gro $\beta)$, se halla tan estrechamente implicado con el interés de la humanidad y su influencia sobre el mundo se ha diseminado tanto por todas partes...» (Id., p. 164; A 150).

$35 \quad$ Id., p. 162 ; A 148.

36 En caso contrario, seríamos víctimas de aquel desenfoque que sufrían aquellos visitantes de las pirámides cuando, ora se acercan mucho, sin alcanzar entonces una aprehensión unificada del fenómeno, ora se alejan demasiado, sin conseguir entonces recibir una impresión suficiente del fenómeno (cfr. nota 30). Siguiendo con la analogía, podríamos decir que «el político» ve la revolución, a veces, desde demasiado lejos: «pues un fenómeno 
de esos espectadores no es netamente entusiasta, no es un entusiasmo del todo participativo, del todo simpático - que sería propio del juicio del gusto ${ }^{37}$-, sino que se limita, es rayano en el entusiasmo, está en el borde, en la frontera, en el límite del entusiasmo, para así precaverse de que, por mor de la grandeza del espectáculo, no seamos invadidos subrepticiamente por la emoción y hasta por el miedo, pero, sobre todo, para dejar libre juego a nuestras capacidades para ir más allá del fenómeno, por grande sin más que éste sea o, mejor, porque éste es grande sin más, y así manifiesta, en el límite, en el borde, la disposición moral de la humanidad.

...que cualquier hombre sensato nunca se decidiese a repetir un experimento tan costoso [...], y, sin embargo, esta revolución - a mi modo de ver- encuentra en el ánimo de todos los espectadores (que no están comprometidos ellos mismos en ese juego) una simpatía (Teilnehmung, o "participación») conforme al deseo que colinda con el entusiasmo (...die nahe an Enthusiasm grenzt) y cuya propia exteriorización llevaba aparejado un riesgo, la cual no puede tener otra causa que una disposición moral (moralische Anlage) en el género humano ${ }^{38}$.

Sólo así podremos vencer al monstruo y retornar del abismo, si es cierto que un juicio de lo sublime es ajeno en su fundamento a cualquier adecuación con un fin determinado, negatividad que, por velar a la sensibilidad y desvelar a la imaginación, permite juzgar el espectáculo de la inconmensurable falta de fundamento, de la mortal aniquilación del fin. Si lo bello es símbolo del bien moral, el respeto estético ante lo sublime, que nos manifiesta la limitación de nuestra imaginación frente a la idea suprasensible, simbolizará — pero según la elevación proyectada de esa inadecuación, «...según la transferencia (Übertragung) desde la reflexión sobre un objeto de la intuición a un concepto totalmente diferente, al que quizá nunca pueda corresponder directamente una intuición ${ }^{39}$ - el respeto moral, que nos hace reconocer la ley presente en

semejante [la revolución] en la historia humana no se olvida jamás (vergißt sich moht mehr), al haber revelado en la historia humana una disposición y una capacidad hacia lo mejor (eine Anlage und ein Vermögen... zum Besseren) que político alguno hubiera podido argüir a partir del curso de las cosas conocidas hasta entonces [...]» (id., p. 164; A 149); en cambio, otras, desde demasiado cerca: «aseguran [nuestros políticos] que se ha de tomar a los hombres tal como son y no como los pedantes ajenos al mundo o los soñadores bienintencionados imaginan que deben ser» (p. 153).

37 Cfr. nota 25.

38 El conflicto de las Facultades, p. 160; A 144-145. «...que el auténtico entusiasmo se ciñe siempre tan sólo a lo ideal y en verdad a lo puramente moral, cual es el caso del concepto de derecho y no puede injertarse al interés personal» (El conflicto de las Facultades, p. 161; A 146).

39 Crit. disc., p. 327; B 257. «What Kant's notion of reflective judgment suggests, without stating it as such, is a situation in which "given" concepts do not suffice to identity or "subsume" the particular case, and hence in which the latter requires a reorganization and reworking of those concepts. If such a reworking is what constituted the a priori principle of judgment, the its product, whether it is cognitive or aesthetic, will always entail an element of change, of transformation. [/] This notion of transformation, never mentioned by Kant, is nonetheless what might be called the deregulative idea of the Third Critique» (Weber, S., Institution 
nosotros, y, en general, el resto de las prenociones estéticas para el deber o disposiciones morales (moralische Anlage, moralische Beschaffenheiten) ${ }^{40}$.

El parágrafo 59 (De la belleza como símbolo de la moralidad) de la tercera crítica establece una analogía entre las intuiciones propias del entendimiento (esquemas), para las que disponemos de un concepto a priori, y las intuiciones relativas a ideas (símbolos), para las que ninguna intuición sería adecuada. Si ambas son intuiciones, los símbolos lo serían por atribución a los esquemas, por cuanto conllevan un juicio que traslada la regla de subsunción de un objeto bajo un concepto hasta una representación distinta:

...una analogía en la que el discernimiento juega un papel doble: en primer lugar, aplica el concepto al objeto de una intuición sensible y, entonces, en segundo lugar, aplica la mera regla de la reflexión sobre aquella intuición a un objeto totalmente diferente, del que el primer objeto es tan sólo el símbolo. De este modo, un Estado monárquico, cuando se rige por leyes populares internas, se representa por un cuerpo animado, pero cuando lo rige una única voluntad absoluta se representa mediante una máquina (como, por ejemplo, un molino de mano), mas en ambos casos sólo se representa simbólicamente. Pues entre un Estado despótico y un molino de mano no hay, ciertamente, ninguna similitud, pero sí la hay entre las reglas para reflexionar sobre ambos y sobre su causalidad (...zwischen der Regel, über beide und ihre Kausalität zu reflektieren $)^{41}$.

La simbolización de un objeto por otro (metáfora) supone un desplazamiento sostenido por el proceder formal o derivación de la aplicación de la regla (metonimia). Si bien esa transferencia no puede considerarse teórica, sin embargo, sí amplía y eleva nuestro conocimiento prácticamente hasta lo suprasensible, con lo que la prelación de la intuición directa (que aparecía como el primer analogado) se cancela, por cuanto la idea simbolizada es investida como principio de determinación, relevando a la impresión sensible traspuesta:

...no son hipotiposis esquemáticas, sino simbólicas, y no son expresiones para conceptos por medio de una intuición directa, sino sólo según una analogía con ella, esto es, según la transferencia desde la reflexión sobre un objeto de la intuición a un concepto totalmente diferente, al que quizá nunca puede corresponder directamente una intuición (...d. i. der Übertragung der Reflexion über einen Gegenstand der Anschauung auf einen ganz andern Begriff, dem vielleicht nie eine Anschauung direkt korrespondieren kann). Si a

and Interpretation. Expanded Edition, Stanford, California, Stanford University Press 2001, p. 142). Parece que sí podemos rastrear en el texto kantiano esa noción de «transformación» o «cambio» en esa «transferencia», «traducción» o «transmisión», Übertragung, que comportaría una doble operación: el olvido de la violencia originaria (espectáculo del patíbulo), por cuanto su intuición resulta en absoluto inadecuada, y su desplazamiento infinito como signo del progreso humano (espectáculo de la revolución).

40 Cfr. los textos de las notas 38 y 50 para referencias a moralische Anlage; cfr., para moralische Beschaffenheiten (el sentimiento moral, la conciencia moral, el amor al prójimo y el respeto por sí mismo o autoestima): Met. Cost., pp. 253s.; A 35.

41 Crít. disc., p. 326; B 257. 
una mera manera de la representación cabe ya denominarla conocimiento (lo cual está permitido cuando no es un principio de la determinación teórica del objeto, de lo que es en sí, sino de la determinación práctica, de lo que la idea de él debe ser para nosotros y para su uso teleológico), entonces todo nuestro conocimiento de Dios es meramente simbólico...42.

Consecuente con ello resulta que se considere lo bello como símbolo del bien (moral), pues si el simbolismo se asemejaba al esquematismo (del entendimiento) por consistir en una presentación del concepto, pero distinguiéndose por cuanto se trataba de un presentación no directa, ni lo bello - basado en la exhibición indirecta—, ni lo bueno — basado en los principios de nuestra razón- estriban en la intuición directa de objeto alguno que los determine esquemáticamente, pudiendo establecerse una analogía (que supone identidad y diferencia) proporcional entre ambos en virtud de la semejanza que les otorga su común inmediatez, desinterés, libertad y universalidad ${ }^{43}$.

Si el discernimiento para juzgar un objeto como bello refiere la imaginación a los conceptos del entendimiento, esa referencia puede desplazarse más allá, hasta las ideas de la razón, pero no por referencia al precedente de la intuición sensible que funcionaría como término real del símbolo, sino, invirtiendo la subrepción -metonimia inversa que remite lo sublime a los objetos naturales- mediante la suspensión de la sensibilidad, suspensión que libera ilimitadamente la transferencia y el libre juego de nuestras capacidades:

Ahora bien, afirmo que lo bello es símbolo del bien moral; y que sólo bajo esta consideración (una relación que le es natural a todo el mundo y que también exige de todos los demás como deber) gusta con una pretensión a la adhesión de todos los demás, donde el ánimo se hace al mismo tiempo consciente de un cierto ennoblecimiento y elevación (Veredlung und Erhebung) sobre la mera receptividad de un placer por medio de las impresiones de los sentidos, y también aprecia el valor de otros según una máxima de su discernimiento. Esto es lo inteligible, hacia lo que [...] mira el gusto, para lo que, en efecto, coinciden incluso nuestras capacidades cognoscitivas superiores, y sin el cual surgirían amplias contradicciones en [entre] la naturaleza de éstas (... zwischen ihrer Natur...), comparada con las pretensiones del gusto. En esta capacidad, el discernimiento no se ve sometido a una heteronomía de las leyes de la experiencia, como sucedería, en caso contrario, en el enjuiciamiento empírico. Pues el discernimiento se da a sí mismo la ley con respecto a los objetos de una satisfacción tan pura, del mismo modo que la razón lo hace con respecto a la capacidad desiderativa. Y tanto por mor de esta posibilidad interna en el sujeto, como por mor de la posibilidad externa de una naturaleza que coincide con ello, se ve referido a algo en el mismo sujeto y fuera de él, que no es naturaleza, tampoco libertad, pero que está enlazado con el fundamento de esta última, a saber: con lo suprasensible, donde de manera colectiva y desconocida la capacidad teórica se unifica con la práctica ${ }^{44}$.

$42 \quad$ Id. pp. 327s., B 257.

43 Cfr. Id. p. 328; B 259-260.

44 Id. pp. 327s., B 258-259. 


\section{Ecos DEL VACÍO}

La exhibición de la máxima inadecuación en su negatividad (el sentimiento de lo sublime), «...en su caos o en su desorden y devastación más salvaje y sin reglas... ${ }^{45}$, es causa de que la capacidad de exhibición (la imaginación) resulte superada y, en cuanto tal, privado nuestro espíritu de cualquier regla de estimación o escala de medida y, por mor de esa privación, las ideas de la razón «...se hacen sentir y se hacen presentes en el ánimo, a pesar de la imposibilidad de exhibirlas adecuadamente, precisamente por esta inadecuabilidad que cabe exhibir sensiblemente (obgleich keine ihnen angemessene Darstellung möglich ist, eben durch diese Unangemessenheit, welche sich sinnlich darstellen läßt, rege gemacht und ins Gemüt gerufen werden)» ${ }^{46}$. Y ello, como prenociones estéticas de la ética.

La libertad de la imaginación posibilita la concordancia entre lo bello y el bien, que depara todo ese ennoblecimiento y elevación de la referencia a las ideas morales. Ésta se acredita en el gusto, instituyéndose su modelo en las humanidades (humaniora), cultura de término medio en el que todos los hombres participamos y del que nos hacemos partícipes (Teilnehmungsgefühl, mitteilen) y que se acomoda a nuestra naturaleza como la ley a la libertad ${ }^{47}$. Sin embar-

45 Crít. disc., p. 202; B 78.

$46 \quad$ Id. p. 201; B 77.

47 "The humanities, for Kant, in this context, entail not so much the cultivation of particular arts, nor even the aims and preconditions of such arts, which Bernard in his translation renders as "sympathy" and "communication". Rather, If I have rendered Teilnehmungsgefühl and mitteilen more literally, as "taking-part" and "imparting", it is in order to render legible what the two German words used by Kant have in common and what I take to be distinctive feature or "property" of the humanities as he invokes them here: partiality. What distinguishes the sphere of the human from the more restrictive one of mere animality is not simply that the former is less limited that the latter, but rather the nature of that limitation: that of a taking-part and of an imparting that never entirely overcomes its particularity.[/] The third Critique can thus be read as inscribing the cultivation or culture of the humanities in precisely the place where the partiality of man partakes and imparts itself by a process of self-effacement that is never entirely successful and that - like Freudian repression, to which it is related in more than one way - always leaves traces.[/] In the light of Kant's text, then, the crisis of the humanities could be understood as an inevitable outgrowth of their aporetic ends: the participation in and imparting of the particular, the partisan, and the partial. At the same time, however, it is precisely this aporetic operation - "the reciprocal imparting of ideas" in Kant's words - that spans a society, from its "most cultivated part" to its "crudest" and holds it together» (WeBer, S., Institution and Interpetation, cit., pp. 143s.). Se trata de esa participación parcial que tiene el filósofo ante la revolución: la del espectador casi entusiasta, que, a la distancia adecuada a la inadecuación del espectáculo, puede convertirlo en signo de los tiempos. Su parcialidad es aquélla del que no toma partido sino desde la barrera, pudiendo así juzgar el espectáculo como-si fuera otro («...we treat the singularities we do not understand as though they were the products of another understanding, like our own and yet unlike it [for it has produced precisely what we do not understand] [.../...] The fictionality of the Kant's als-ob, the "as-if", thus becomes the condition of all knowledge of the particular. But it is a singular condition, one we "assume" without "really" assuming it, since it is 
go, esa armonía está lejos de ser algo granjeado de partida; por el contrario, la humanización que supone la participación habría consistido en un dinamismo conflictivo entre partes:

Tanto la época como los pueblos en los que el impulso que conduce hacia la sociabilidad conforme a leyes (mediante la cual un pueblo consitituye una comunidad duradera) lucha contra las grandes dificultades que circundan la difícil tarea de unificar la libertad (y, por tanto, también la igualdad) con una coerción (más del respeto y el sometimiento por deber que por miedo [aus Furcht]), tanto una época tal como un pueblo tal debió ante todo descubrir el arte de la recíproca comunicación de las ideas (...die Künst der wechselseitigen Mitteilung der Ideen des ausgebildeten Teils...) de la parte más cultivada con la parte más tosca, la sintonización de la amplitud y el refinamiento de las primeras con la ingenuidad y originalidad natural de las últimas y, de este modo, debió descubrir aquel término medio (Mittel) entre la más elevada cultura y la sobria naturaleza, que también constituye el patrón de medida correcto, que no cabe dar según regla universal alguna, para el gusto, en tanto que sentido humano universal (...welches den richtigen, nach keinen allgemeinen Regeln anzugebenden Maßstab auch für den Geschmack, als allgemeinen Menschsinn, ausmacht $)^{48}$.

La reconciliación entre libertad y naturaleza supone la resolución y el valor del sentimiento de lo sublime — para catar el fruto prohibido de la libertad-, condición trascendental para que pueda llegarse a ese gusto en el que se armoniza la sensibilidad con el sentimiento moral. Si la simbolización de lo bueno por lo bello, esto es, la transición (Übergang) de la sensibilidad a lo moral no habrá de suponer un salto demasiado violento (...ohne einem zu gewaltsamen Sprung... $)^{49}$, por contra, el sentimiento de lo sublime exige esa transferencia (Übertragung) infinita, en la que el esquematismo y hasta el simbolismo de la adecuación son superados y relevados por la exhibición estremecedora de la inadecuación - como la ejecución del monarca. Si la difícil tarea de la autonomía afecta al discernimiento (juicio, Urteilskraft) y a la razón en paralelo, por cuanto ambos se dan a sí una ley que no procede de la intuición sensible, el sentimiento de lo sublime será el catalizador del progreso de la receptividad para la razón, que entusiasma, o casi, a quien, exponiéndose, sin exponerse del todo, presencia liminarmente la ruptura de la concordancia con la sensibilidad para, justo después de esa interrupción, sincopar la discordancia por obra de la razón.

Hay innumerables cosas de la bella naturaleza sobre las que pretendemos que el juicio de todo el mundo concuerde con el nuestro, lo cual también podemos aguardar sin pretender por ello nada extraordinario. Pero con nuestro

\footnotetext{
"only" what we might call a "heuristic device"» [p. 150]). Ese «heuristic device» corresponde al Anstrich de la ejecución del monarca, en definitiva, a la ficcionalidad para la que se exige resolverse. Sin embargo, tratándose del sentimiento de lo sublime, el «como-si» supone la habilitación del «another understanding» como voz de la conciencia - Otro interior (cfr. infra).

48 Crít. disc., p. 330; B 262-263.

49 Cfr. Crít. disc., p. 329; B 260.
} 
juicio sobre lo sublime de la naturaleza no podemos prometernos un acceso tan fácil a los demás, pues para poder emitir un juicio sobre esta superioridad de los objetos de la naturaleza parece exigirse una cultura mucho más amplia, no sólo del discernimiento estético, sino también de las capacidades cognoscitivas que están en su fundamento.

$[\ldots]$

Pero precisamente porque el juicio sobre lo sublime de la naturaleza requiere cultura (más que el juicio sobre lo bello), precisamente por ello, no lo crea primeramente la cultura para introducirlo luego en la sociedad, por ejemplo, de manera meramente convencional, sino que tiene su fundamento en la naturaleza humana y, ciertamente, en aquello que todo el mundo puede pretender y exigir con su sano entendimiento, a saber, en la predisposición para las ideas morales (...in der Anlage zum Gefühl für [praktische] Ideen, d. i. zu dem moralischen $)^{50}$.

Y si exigimos tanto la aprobación universal del juicio sobre lo bello como del juicio sobre lo sublime, ello:

con la diferencia de que lo primero lo exigimos de todo el mundo, puesto que aquí el discernimiento refiere (bezieht) la imaginación al entendimiento en tanto que capacidad de concepto; lo segundo, sin embargo, puesto que aquí el discernimiento refiere la imaginación a la razón pero la referencia ya no será concordancia en tanto que capacidad de ideas, lo exigimos sólo bajo una presuposición subjetiva (que, sin embargo, creemos estar justificados para poder reclamar de todo el mundo), a saber, la presuposición del sentimiento moral en el ser humano (des moralischen Gefühls im Menschen). En esta medida, también atribuimos necesidad a estos juicios estéticos.

En esta modalidad de los juicios estéticos (a saber, la necesidad adecuada [angemaßten] a ellos) reside el momento principal de la crítica del discernimiento ${ }^{51}$.

La compleja operación de lo sublime - exhibir lo inexhibible, violentando la imaginación, al abismarla/elevarla- se estipula como condición trascendental del gusto y, en cuanto tal, de la sensibilización de las ideas morales y de su canon humanístico. De resultas de tal exhibición privativa, el fundamento de la ley estará allí donde no se pueda ver, en aquel fundamento oculto desde el que la imaginación recibía su amplificación (deren Grund aber ihr selbst verborgen $i s t)^{52}$, en el agujero insondable que ha abierto la muerte del soberano-padre, boca desde la que se enuncia la ley que resuena en el abismo del corazón.

El autoconocimiento moral, que exige penetrar hasta las profundidades del corazón más difíciles de sondear (el abismo) (...in die schwerer zu ergründende Tiefen [Abgrund] des Herzens...), es el comienzo de toda sabiduría humana. Porque esta última, que consiste en la concordancia de la voluntad de un ser con el fin final, exige del hombre ante todo apartar los obstáculos internos (de una voluntad mala que anida en él) y desarrollar después en él la

$50 \quad$ Id. pp. 224s.; B 110-112.

51 Id. p. 226, B 112.

52 Cfr. pp. 229s; B 117. 
disposición originaria inalienable (der nie verlierbaren ursprünglichen Anlage) de una buena voluntad (sólo descender a los infiernos del autoconocimiento abre el camino a la deificación) (nur die Höllenfhart des Selbsterkenntnisses bahnt den Weg zu Vergötterung) ${ }^{53}$.

El miedo real a que la posible reacción monárquica acabe con la vida del republicano conduciría a investir el asesinato como procedimiento jurídico, con lo que se escenifica la contradicción e inversión del orden simbólico (ley). Esa es la escena monstruosa ofrecida al espectador filosófico -más o menos seguro desde su mirador intelectual — que le da ocasión para experimentar un estremecimiento imaginario (asombro, fascinación) y así poner en marcha, que no en juego, el poder de su razón para voltear esa violencia infinita ${ }^{54}$. La inversión normativa exhibida en la ejecución real se invierte, entonces, ella misma, cerrándose sobre sí, por cuanto aquélla violencia que experimenta el individuo subjetivamente al representarse el abismo de la ley, es utilizada como herramienta por la razón (als einem Werkzeuge der Vernunft), tanto para probar el poder de lo suprasensible sobre lo sensible, como para revelar la oculta ordenación de nuestra imaginación - y, en cuanto tal, de nuestra libertad- a un uso racional (disposición moral): «en esta medida, la satisfacción en lo sublime de la naturaleza es tan sólo negativa (mientras que la satisfacción en lo bello es positiva), a saber, un sentimiento de privación de la libertad de la imaginación por medio de ella misma, en la medida en que se determina teleológicamente según otra ley que la del uso empírico» ${ }^{55}$. En ese vacío (de la ley) que determina la negatividad de la violencia ejercida sobre la imaginación (la privación del rapto sufrido por la imaginación) aquel miedo instintivo resulta sublimado, una vez muerto el padre-soberano, como miedo simbólico, al religar simbólicamente la imaginación con el respeto por la ley como conciencia moral. Lo informe que causa el sentimiento de lo sublime, displacentero y placentero, estructura al sujeto en torno a la conmutación de la diferencia interior/exterior en identidad/ alteridad, realoja en su interioridad aquel miedo del que la distancia preservaba y espacia su intimidad como caja de resonancia de la ley moral (yo como otro):

Todo hombre tiene conciencia moral y un juez interno le observa, le amenaza, le mantiene en el respeto (überhaupt im Respekt), respeto unido al miedo (mit Furcht verbundener Achtung) y este poder (Gewalt), que vela en él por las leyes, no es algo que se forja (arbitrariamente), sino que está incorporado en su ser. Le sigue como su sombra cuando piensa escapar. El puede ciertamente aturdirse o adormecerse con placeres y diversiones, pero no puede evitar volver en sí o despertar tan pronto como oye su temible voz (die furchtbare Stimme). El hombre puede llegar en su extrema depravación hasta no hacerle ningún caso pero, sin embargo, no puede dejar de oírla ${ }^{56}$.

53 Met. Cost., p. 307; A 104. En nota al paréntesis final de la ed. española: «Tomado de Hamann, "Abelardi Virbii Chimärische Einfälle", Roth II, 198. Vid. también Streit, VII, 55 29-30".

54 Cfr. nota 25.

55 Crít. disc., p. 229; B 117.

56 Met. Cost., p. 303; A 99. 
De modo análogo — pero aquí el problema, recuérdese, es la analogía-, cuando la imaginación es desbordada por una cantidad infinita, «...el ánimo escucha en sí la voz de la razón (die Stimme der Vernunft), que exige totalidad para todas las magnitudes dadas, incluso para aquellas que, ciertamente, nunca pueden aprehenderse totalmente... ${ }^{57}$.

\section{Abducciones de Lo SUblime}

Lo sublime de la revolución releva a lo monstruoso de la ejecución del príncipe - la aniquilación del fin, la inversión del derecho- cuando el ilustrado se resuelve a aprehender el espectáculo como aura (Anstrich) del derecho antes que como velo del crimen. Guardando la debida distancia para no ser víctima del efecto patológico del miedo, consigue, de un trazo (Strich), desprender el efecto sensible de la intuición de la afección subjetiva de nuestro ánimo. La imaginación resulta expuesta a esa ese máximum que excede los umbrales de la representación sensible y que no es sino la sombra de las ideas de la razón, la cual dilata y eleva hasta el gálibo de la ley suprasensible a aquélla, la imaginación, en el sentimiento de lo sublime. La conmoción brutal que el espectáculo del ajusticiamiento provoca cuando es imaginado como una inversión del derecho, un vértigo repulsivo por el desafuero padecido por la imaginación, pero atractivo por el aforamiento granjeado por la razón: un gozo masoquista del deseo del otro en nosotros (la ley moral), que mide lo inmensurable, que puede a lo totipotente. De ese modo, se desplaza y re-emplaza... ¿subrepticiamente?, se sublima, el lugar vacante del Otro, de la ley, abriéndose así el espacio para la narratividad del tiempo humano (historia moral): «este acontecimiento no es el fenómeno de una revolución, sino (como dice Erhard) de la evolución de una constitución iusnaturalista que, aun cuando sólo se logre en medio de salvajes contiendas [...] nos hace sin embargo propender hacia una constitución que pueda no ser bélica, o sea, la republicana.... $\gg^{58}$. La representación de ese acontecimiento se transmuta en signo de la institución de la historia moral, según la cual se reconciliarán naturaleza y libertad jurídicamente. Si bien un hombre sensato (wohldenkender Mensch) no la repetiría una segunda vez, no obstante no se olvida jamás,

pues ese acontecimiento es demasiado grandioso (zu gro $\beta)$, se halla tan estrechamente implicado con el interés de la humanidad y su influencia sobre el mundo se ha diseminado tanto por todas partes, como para no ser rememorado por los pueblos en cualquier ocasión donde se den las circunstancias propicias y no ser evocado para repetir nuevas tentativas de esa índole; pues al tratarse de un asunto tan importante para el género humano la proyectada constitución ha de alcanzar finalmente en algún momento aquella firmeza

57 Crít. disc., p. 211; B 91.

58 El conflicto de las Facultades, p. 163; A 148-149. 
que la enseñanza no dejará de inculcar en el ánimo de todos mediante una experiencia cada vez más frecuente ${ }^{59}$.

Un sentimiento, pues, compartido por todos y que algunos imparten, tal como ocurría con los conocimientos de las humanidades o conocimientos previos adecuados a la humanidad, aquéllos que granjean, según la primera edición de la tercera crítica, la sociabilidad (Geselligkeit), y según la segunda, la felicidad (Glückseligkeit). No obstante, la rememoración del acontecimiento revolucionario al que se ha de dar publicidad tiene su condición en un olvido, en la represión de aquel dolor y violencia que impedían que el revolucionario sensato, en la inmediatez del acontecimiento, olvidara y repitiera, a diferencia del filósofo ilustrado, que a la distancia conveniente del espectáculo, puede olvidar el hecho que queda más allá de los límites de lo exhibible (la ejecución del monarca), pero para rememorarlo como acontecimiento transfigurado por la razón (el progreso moral) ${ }^{60}$. Pero, ¿cómo gira ese aquí y allá de la memoria, ese olvido que se recuerda, ese recuerdo que se olvida?

La tala de la genealogía como ejecución del soberano y el injerto de la autofundación del poder político interfieren. Soberano y súbditos, padre y hijos, son tragados por esa ejecución de la ley que invierte diametralmente el orden de la relación, resultando el legado detenido y suspendido, sin sucesión, salvo que el heredero interiorice la escisión y se divida en dos para ejecutar la obligación (la ley de la existencia) como propia, transfiriéndola del pecho del Otro (in scrinio pectoris sui) al corazón propio. Pero para ello se habrá de subrogar la ejecución del soberano, la ejecución del Otro, como muerte propia (un suicidio cometido por el Estado, como se tildaba la ejecución del monarca ${ }^{61}$. Si el regicidio es simbólicamente un parricidio, el parricidio es simbólicamente un

$59 \quad I d .$, p. 164; A 150.

60 «...saber cómo se memoriza una muerte plantea un problema, aunque esta memorización permanezca en cierto modo implícita, o sea, es propio de la naturaleza de la memorización que el hecho sea olvidado por el individuo, trátese del asesinato del padre o del asesinato de Moisés. Es propio de nuestra mente olvidar lo que sigue siendo absolutamente necesario como clave, como eje alrededor del cual ella misma gira»: El seminario de Jacques Lacan. Libro 5. ed. cit., 2009 ( $8^{\text {a }}$ reimpr.), p. 318.

${ }^{61}$ Cfr. Legendre, P., «Le sujet du suicide», en Legendre, P., Leçons IV, suite 2. Filiation. Fondement généalogique de la psychanalyse par Alexandra Papageorgiou-Legendre, Fayard 1990, pp. 211-221. Allí, recorriendo a la inversa el camino, se entiende el suicidio como un parricidio. Se arranca de una consideración aritmética: «...si le suicide est à la fois auteur et victime d'un homicide, cela veut dire qu'il est deux. Dès lors, que signifie être deux, dans le cas du sujet humain? (p. 213). Y remata en una consideración contable: «l'idée de paiement suppose una dette, par conséquent un créancier et un débiteur [...] l'enfant est créancier queant à la représentation du Père, et c'est le père [...] qui est débiteur en titre: il doit au fils un paiement sous la forme de lui infliger la limite, c'est-à-dire de le fonder symboliquement comme sujet séparé de la mère [...]. Dans cette perspective, un suicide [...] laisse parfois transparaître l'accident de la représentation auquel succombe le sujet qui se tue: payer à la place de, payer l'indu pour enfin se fonder» (p. 220). 
suicidio. Sólo así, por el sacrificio, por el auto-sacrificio, se podrá repetir la ley en (el) lugar de su origen ${ }^{62}$.

Esta disposición originaria, intelectual y moral (porque es una representación del deber), llamada conciencia moral (Gewissen), tiene en sí de peculiar que, aunque ésta su tarea es un quehacer del hombre consigo mismo, sin embargo, éste se ve forzado por su razón a desempeñarla como si fuera por orden de otra persona (es als auf das Gehei $\beta$ einer anderen Person zu treiben). Porque el asunto consiste aquí en llevar una causa jurídica (causa) ante un tribunal. Pero representar al acusado por su conciencia moral como una y la misma persona (als eine und dieselbe Person vorgestellt werde) que el juez, es un modo absurdo de representar un tribunal, porque en tal caso el acusador perdería siempre. - Por tanto, en todos los deberes la conciencia moral del hombre tendrá que imaginar (denken müssen) como juez de sus acciones $a$ otro (como hombre en general), distinto de sí mismo, si no quiere estar en contradicción consigo mismo (...wenn es nicht mit sich selbst im Widerspruch stehen soll) ${ }^{63}$.

[Artículo aprobado para publicación en noviembre de 2013]

62 «...el auto-sacrificio remite a una culpa de sangre. Y si ese sacrificio de la propia vida produce la reconciliación con Dios Padre, el crimen así expiado no puede haber sido otro que el parricidio.[/] En el acto mismo de ofrecer al padre la mayor expiación posible, el hijo alcanza también la meta de sus deseos en contra del padre. El mismo deviene dios junto al padre, en verdad en lugar de él (...eigentlich an Stelle des Vaters)» (Freud, S., Tótem y tabú, en Obras completas. Volumen 13 (1913-14), Buenos Aires - Madrid, Amorrortu editores 2008, p. 155).

63 Met. Cost., pp. 303s; A 100. 
